\title{
EXPERIÊNCIA DE UMA EQUIPE DE SAÚDE MENTAL COMUNITÁRIA NA ASSISTÊNCIA DE FAMÍLIAS CONVIVENDO COM A DEPRESSÃO
}

\author{
FAMILIES LIVING WITH THE DEPRESSION: \\ THE EXPERIENCES OF A COMMUNITY MENTAL HEALTH PROFESSIONALS
EXPERIENCIA DE UN EQUIPO DE SALUD MENTAL COMUNITARIO EN LAASISTENCIA DE FAMILIAS QUE CONVIVEN CON LADEPRESIÓN

\author{
Maria Concepción Pezo Silva* \\ Maguida Costa Stefanelli**
}

\begin{abstract}
RESUMO: A depressão vem aumentando progressivamente na sociedade e atinge não só o seu portador mas também sua família, fatos que a tornam prioridade do atendimento em nível primário. Nosso objetivo foi conhecer como os integrantes de uma equipe interdisciplinar descrevem sua experiência de trabalho com famílias convivendo com a depressão.Valemo-nos do método etnográfico e para obtenção de dados utilizamos um formulário com uma pergunta aberta seguida de um roteiro. Construímos como categorias culturais: "Enfatizando aspectos culturais", "Apontando a demora da família para perceber as manifestações das pessoas com a doença", "Relatando suas ações", "Comentando a interação com a família" e o tema cultural : "Integrando uma equipe apesar das diferenças". Segundo o estudo, embora os membros consigam manter um trabalho de equipe interdisciplinar, a experiência é descrita segundo a visão ou função de cada um. Apesar disto eles conseguem obter a informação global do paciente num clima de respeito mútuo considerando a complementaridade de saberes.
\end{abstract}

PALAVRAS-CHAVE: Equipe de assistência ao paciente; Família; Depressão.

\section{INTRODUÇÃO}

O aumento de transtornos mentais, entre eles a depressão, no mundo é uma evidência que vem sendo citada por vários estudiosos da área (Almendras, 2001; Moreno e Moreno, 1999; WHO, 1999).

A Organização Mundial da Saúde em estudo sobre o "ônus global das doenças" considerou cinco transtornos mentais, dentro das dez primeiras causas que provocam incapacidade, em âmbito mundial (WHO,1999). A depressão maior ocupou, em 1998, o quinto lugar e há projeção para o segundo, no ano 2020, se persistir a atual tendência. A depressão ocasiona maior sofrimento e comprometimento. Os custos acarretados pela doença e suas conseqüências, como perda de emprego, diminuição da produtividade no trabalho e mortalidade por suicídio são incalculáveis (Huamán, 1996; Kaplan etal., 1996; Macher, 1996).

R evendo a literatura podemos afirmar que até 1994, a tônica desta assistência ainda era acentuadamente hospitalocêntrica. (Stefanelli et al., 1994) A nosso ver se esta não for adequada pode dar como conseqüência a cronificação da doença e a aparição da síndrome da porta giratória. De 1994 até os dias atuais vários trabalhos têm surgido, apresentando uma diversidade de estratégias de atendimento em todos os níveis, tendo-se percebido que, o trabalho em equipe está subjacente à quase todos ou pelo menos é citado, haja vista os trabalhos de Pezo Silva e Stefanelli (1991).

* Enfermeira. Professora Principal da Faculdade de Enfermagem da Universidade Nacional Pedro Ruiz Gallo - Lambayeque - Perú. Aluna do Programa de Doutorado da Escola de Enfermagem da Universidade de São Paulo.

** Professora Titular pela Universidade de São Paulo (USP). Orientadora do Programa de Doutorado da Escola de Enfermagem da USP. Assessora do Conselho Diretor do Instituto de Psiquiatria do Hospital das Clínicas da Faculdade de Medicina da USP (IPq HCFMUSP). 
Em informe realizado pelo Instituto Nacional de Salud Mental "Honório Delgado-Hideyo Noguchi" (1995) sobre a orientação da assistência psiquiátrica na América do Sul encontramos dados que, aberta ou veladamente, ainda podem ser observados na área psiquiátrica. Alguns fatos confirmam que apesar do tempo decorrido, da publicação do referido informe até nossos dias, nada ou quase nada se tem feito para mudar este panorama. Entre estes temos diminuição da prioridade do setor saúde para a saúde mental; prática profissional com tendência à individualidade em alguns países e multiprofissional em outros; assistência voltada para a recuperação; 0 elevado custo dos medicamentos; internações curtas para os casos agudos ou reagudizados e longas para pacientes crônicos; o cenário do ensino psiquiátrico majoritariamente feito em hospitais psiquiátricos e, entre outros, a escassa participação da comunidade como reflexo da pouca vinculação entre ela e o setor saúde.

A atenção primária, ressaltada desde Alma-A ta em 1978, inclui a comunidade que é, há muito, o foco de atenção, enfatizado pela OMS e OPS (1995) pois constitui-se, no caso da saúde mental, o lugar propício para estarmos iniciando ações de promoção da saúde e prevenção da doença, através de atividades psicoeducativas que favoreçam o estabelecimento de estilos de vida saudáveis na família, relacionamento e envolvimento em redes de suporte social onde possam recorrer na procura de ajuda, entre outras atividades.

E m estudo realizado por Pezo Silva; Stefanelli (1991) foi encontrado que, a falta de um trabalho com a família na comunidade e em equipe interdisciplinar estão dentro dos fatores que contribuem à reinternação dos pacientes psiquiátricos.

Temos, entretanto, observado uma lenta transição nos modelos de atendimento, existindo fatores contribuindo para isto. Cabe considerar, entre eles, aspectos econômicos, sociais e culturais que caracterizam os países em desenvolvimento como tendo influência negativa acentuada, sobre o desenvolvimento integral do ser humano e o acesso aos serviços do sistema de saúde. Exemplificando, citamos a pobreza e os fatores a ela associados, que atingem cifras alarmantes nos países em desenvolvimento. Podemos citar o Peru, no qual aproximadamente $054 \%$ da população vive em situação de pobreza, sendo 21,7\% em extrema pobreza (Instituto Nacional de Estatística e Informática, 2001 apud Ministerio de S alud, 2002).

$\mathrm{Na}$ realidade, o transtorno mental é envolvido no emaranhado de dimensões do ser humano, o que faz com que um atendimento eficiente só seja possível por meio de equipe interdisciplinar. A interdisciplinaridade e 0 trabalho na comunidade é um recurso que pode acelerar o processo de transição e também, uma forma de enfrentamento da escassez de recursos humanos e institucionais existentes em países em vias de desenvolvimento. Deste modo, as dimensões biológicas, psicológicas, sociais, culturais, espirituais e intelectuais podem ser atendidas e também utilizadas para potencializar o efeito das ações da equipe interdisciplinar.

Fundamentadas em Stuart (2001) e em algumas considerações de Stefanelli et al. (1985), apresentamos a seguir um conceito de equipe interdisciplinar.

Equipe interdisciplinar, em saúde mental, é aquela na qual os membros atuam de forma planejada, integrada e coerente, num esforço comum, para maximizar a recuperação do paciente e família, cientes cada um do seu papel e o dos outros, usando o conhecimento de forma compartilhada para a consecução de objetivos comuns.

A composição da equipe interdisciplinar em saúde mental, de uma forma geral engloba o médico psiquiatra, a enfermeira, o psicólogo, 0 assistente social e a terapeuta ocupacional.

Em alguns serviços de saúde mental, às vezes, encontramos outros elementos como arteterapeuta, nutricionista, professor de educação física, musicoterapeuta entre outros.

$P$ ara ilustrar este trabalho realizamos um estudo com a equipe interdisciplinar comunitária que atua em consultórios de saúde mental de três Centros de Saúde, sob a jurisdição do Instituto Nacional de Salud Mental Honório Delgado-Hideyo Noguchi de Lima, Peru.

Com base nas considerações feitas, nosso objetivo é, para este estudo, descrito a seguir. 


\section{OBJ ETIVO}

Compreender a experiência vivida pelos integrantes de uma equipe interdisciplinar comunitária no atendimento da pessoa portadora de depressão e sua família.

\section{MÉTODO}

TIPO

Trata-se de um estudo qualitativo, tipo etnográfico. Este tipo de pesquisa nos permite conhecer o que um grupo cultural vivencia no seu ambiente natural, segundo seus padrões de comportamento, suas crenças e valores. Os dados e categorias emergem das falas dos informantes.

\section{CENÁRIO}

O cenário foi constituído de consultórios de Saúde Mental de três Centros de Saúde do Ministério da Saúde, localizados nas zonas periféricas de Lima, Peru. É nestes que o paciente e família, que apresentam transtornos mentais são atendidos pela equipe interdisciplinar. C abe esclarecer que nenhum consultório conta com uma equipe interdisciplinar completa, pelo número insuficiente de recursos humanos profissionais nesta área. Esta falta, porém, é preenchida através da escala estabelecida de alguns profissionais, principalmente psiquiatra e psicólogo, para cada consultório de saúde mental, sendo que a presença da enfermeira, técnica de enfermagem, assistente social e terapeuta ocupacional é permanente nos diferentes consultórios. 0 atendimento dos aspectos de saúde mental está diretamente sob responsabilidade do Instituto Honorio Delgado - Hideyo Noguchi, através de seu Departamento de Saúde Mental comunitária. Este inclui em suas atividades gerais a promoção da saúde mental, prevenção da doença mental, o atendimento dos usuários e as ações de reabilitação.

\section{INFORMANTES}

A amostra teórica deste estudo foi composta por Enfermeiras (4), Psiquiatra (1), Assistentes Socia is (2) e Psicólogo (1). A média de idade dos informantes é de 45 anos; o tempo médio há que estão formados é 20 anos e trabalham nos consultórios de saúde mental, em média, há 20 anos.

\section{OBTENÇÃO DE DADOS}

Utilizamos como instrumento de coleta de dados a entrevista com uma pergunta aberta e roteiro esclarecedor: Descreva qual é a sua experiência na assistência da pessoa portadora de depressão e de sua família. As entrevistas se realizaram no próprio consultório de saúde mental fora dos horários da assistência aos pacientes com consulta agendada, e as respostas foram gravadas com a prévia autorização dos respondentes.

\section{ASPECTOS ÉTICOS}

Foram obedecidas as normas do Instituto Nacional de Salud Mental Honorio Delgado-Hideyo Noguchi. Informamos aos participantes sobre sigilo, anonimato, liberdade de participação ou não na pesquisa e o uso que se faria dos dados. 0 Consentimento Livre Pós-Informado só foi assinado após validação da compreensão das informações. Foi assumido o compromisso de retorno dos resultados do estudo aos informantes e à Instituição. 


\title{
ANALISE DOS DADOS
}

A pós algum tempo de convivência com os dados elaboramos as categorias culturais e o tema cultural emergiu da reflexão sobre este. Ambos são descritos a seguir.

\author{
Categorias culturais \\ "Enfatizando aspectos culturais". \\ "Apontando demora na percepção da doença pela família". \\ "R elatando suas ações". \\ "Comentando a interação com a família". \\ Tema cultural \\ "Integrando uma equipe apesar das diferenças".
}

\section{APRESENTAÇÃO DAS CATEGORIAS}

A análise dos dados obtidos permitiu-nos identificar uma variedade de experiências dos informantes a partir das atividades realizadas, no seu cotidiano, nos consultórios de saúde mental. As categorias revelam as descrições dos profissionais a respeito de como as famílias percebem o transtorno mental, primeiras medidas tomadas e quem toma as providências para o atendimento da pessoa deprimida, apesar da tendência a considerar a doença como fuga da realidade, preguiça e ócio.

\section{"Enfatizando aspectos culturais"}

Algumas falas mostram aspectos culturais permeando a maneira de conceber e tratar a doença de quem procura ajuda dos profissionais. Por exemplo, o psiquiatra refere não proibir aos pacientes a prática de rituais religiosos, a ingestão de ervas sob forma de chás ou infusões ou qualquer outra prática caseira, desde que não interfiram com o tratamento médico ou que este último não seja proibido pelo "curandeiro". Caso isto aconteça, o médico recomenda para deixá-la e ficar apenas com o tratamento do especialista.

Ainda, dentro do contexto cultural, outros membros da equipe manifestaram ter observado o "machismo", a submissão da mulher e a violência cometida contra ela e as crianças, como sendo característica própria da cultura, apreendida e interiorizada desde os primeiros anos de vida, na família. Uma das enfermeiras considerou estas características como parte de uma cultura rígida. Incluem, ainda, aspectos relacionados com crenças, mitos quanto à criança e educação dos filhos.

"A família geralmente atribui, a mudança no comportamento, aos conflitos e problemas econômicos. Encontramos, porém, alguns que acreditam que o problema de saúde deve-se à bruxaria". (Assistente Social B)

"Tenho encontrado famílias que dizem que o extrato de rã é bom para tudo. Isso é uma questão cultural da zona de procedência, como a do interior do país". (Psiquiatra)

"Se me dizem que lhes sugeriram tomar banhos de nata do leite porque é bom, eu aceito... se me dizem que Ihe fizeram imposição de mãos um grupo católico carismático... eu digo pode seguir indo. Mas eu faço a advertência de que se algum deles Ihes diz 'o que vocêestá tomando é droga, são químicos, deixa de tomá-los e você vai ver como sara'... então aí eu recomendo não darem importância". (P siquiatra)

"Geralmente quando eu intervenho, eles já passaram pelos curandeiros e todas "essas coisas". Em algumas situações há tratamento paralelo mas, eu alerto sempre: "não bebam qualquer coisa que thes 
ofereçam". Eu lhes pergunto que ervas são, quanto tempo as fervem, a cada quanto tempo as bebem. Depois desse interrogatório sugiro-Ihes que com essa infusão tomem seu comprimido ." (Psiquiatra).

“Quando falo de 'cultura rígida' estou me referindo aos aspectos de formação recebidos em casa, ou seja, onde a família tem apreendido padrões rígidos de comportamento como: 'Tens que comportar-te assim... tu és mulher, portanto, tens que aprender a lavar, cozinhar, passar roupa, ... você vai ter um marido a quem atender e mesmo que te maltrate, terás que continuar com ele... pior ainda se tens filhos... teu marido é teu marido, do contrário te abandonará e teus filhos crescerão sem pai; O que você faz com filhos sem pai? Teus filhos se perdem'. Se um pai ou uma mãe têm sido educados sob este esquema, ele passa a formar parte de seu padrão de comportamento. Tirar isto da sua cabeça, vai causar-Ihe medo, pois cresce com uma baixa auto-estima, terá medo de valer-se por si própria. Por isso, para sentir-se protegida precisa estar apoiada na imagem masculina"... (Enfermeira C)

"Desde que começou o trabalho com aspectos de violência familiar, temos detectado muitíssimos casos de depressão, que até nos falta tempo para atendê-los. De acordo com minha experiência, penso que 0 fundo de uma depressão é um problema de violência familiar". (Enfermeira B)

“A pessoa criada sob padrões culturais rígidos adotará uma atitude conformista. Dirá talvez: 'o que vou fazer... assim ficarei pois... que má sorte tive... por que Deus me tem feito isto? Eu sou boa... sou boa mãe, faço tudo em casa... por que meu esposo me trata mal?.' Esta é uma coisa cultural que influi na emergência de problemas depressivos, na mulher". (Enfermeira C)

Dados sobre aspectos culturais, também, foram encontrados por Pezo Silva, Stefanelli e Arantes (2001) em um estudo realizado com famílias no norte do Peru, zona caracterizada pela prática da medicina folclórica. As autoras descrevem a trilha que a família persegue na procura de atendimento do familiar deprimido. As descrições realizadas pelos profissionais da equipe multidisciplinar confirmam os dados encontrados pelas referidas pesquisadoras. Os dados revelam que a procura do clínico geral ou o especialista, é majoritariamente após práticas caseiras, religiosas ou rituais realizados pelos curandeiros. Observamos, porém, que estes dados não são fornecidos abertamente por familiares ou pacientes. Só depois de um breve interrogatório e a criação de um ambiente de confiança, eles relatam suas experiências prévias. P rovavelmente isto se deva ao temor de serem rejeitados ou punidos, pelos profissionais de saúde, ao manifestarem suas crenças e a prioridade dada a essas práticas, apesar de sabermos que, o curandeirismo, é uma prática transmitida de geração em geração e elemento constitutivo do acervo cultural de um povo.

Existem, entretanto, outras razões para esta primeira procura, como a descrita por Capra (1982) ao referir que os curandeiros adotam abordagens diferentes que 0 autor considera holísticas em diferentes graus ou usam uma ampla variedade de técnicas terapêuticas. Acrescenta que essas cerimônias envolvem usualmente uma intensa relação entre o curandeiro e o paciente. Isto nos leva a pensar que, no curandeiro, as pessoas encontram alguém que fala o mesmo idioma deles, compartilham crenças comuns e é sensível a seus problemas emocionais, aspecto este que, em geral, não observamos no atendimento à saúde.

"Apontando demora na percepção da alteração do comportamento como doença"

A demora na percepção pela família da depressão como doença e as mudanças de comportamento havidas, foi apontada pela enfermeira e o psicólogo como fatores que retardam a procura de atendimento. As manifestações físicas e psicológicas da depressão enquanto não percebidas como doença, são consideradas pela família como preguiça, malcriação, ociosidade, fraqueza, bobagem. Esta forma de conceber a doença, ainda não reconhecida como tal, leva à família a passar por alto ou desconhecer o quanto a depressão afeta no 
desempenho das atividades do dia-a-dia em casa, nos estudos ou no trabalho do familiar que a padece, bem como nas relações com as pessoas de seu entorno social e familiar. Em outros casos o membro da família fica surpreso diante do diagnóstico fornecido e, apesar deste ser referido pelo próprio profissional, nega-se ainda aceitá-la como sendo uma doença.

Com o decorrer dos dias, os sintomas acentuam-se cada vez mais, fato que leva os familiares a procurarem ajuda, geralmente, seguindo uma ordem hierárquica: médico clínico-psiquiatra; curandeiro - médico clínicopsiquiatra, por colocar os mais comuns (Pezo Silva e Stefanelli, 2001).

Esta demora na procura de atendimento especializado deve-se, segundo Mendoza M. et al. (2000), ao preconceito existente a respeito do uso dos serviços de saúde mental, considerados locais para assistir "loucos", à falta de recursos econômicos para o transporte e pago da consulta, à baixa reputação concedida a alguns estabelecimentos estatais de saúde em relação ao atendimento neles recebidos se comparados com o atendimento destes mesmos profissionais na consulta particular, à falta de maior difusão dos serviços que prestam as instituições psiquiátricas para casos de depressão, à automedicação com fármacos como o diazepam e uso de ervas medicinais perante as primeiras manifestações.

"Há pacientes que são deprimidos mas, muitas das vezes, sua família pensa que o que tem é uma bobagem, uma fraqueza da pessoa. É por isto que a família não o motiva e nem o paciente vai procurar tratamento". (Enfermeira)

"Para os familiares, se não existem suficientes sintomas, ou seja, se a doença não é aguda, então é um problema que não justifica a procura do médico". (Enfermeira B)

"Só quando o paciente apresenta somatizações que impedem desenvolver sua vida cotidiana (estudo, trabalho, interrelação social e familiar) a família e paciente vão ao consultório. Este grupo de pacientes constitui 15\% da população". (Enfermeira B)

"Quando chamamos a mãe do adolescente com depressão, ela se surpreende pois não o vê como problema. Em outras palavras não o valoriza, não quer reconhecer o problema depressivo, não presta atenção, pensam que é uma atitude de malcriação". (Psicólogo)

“...Eles dizem que a pessoa se faz de doente, é um ocioso e como não gosta trabalhar se faz de doente para não ser obrigado". (Assistente Social A)

"Temos observado muita crítica, desvalorização, negação e outras vezes superproteção por parte da família em relação à doença". (Assistente Social B)

\section{"Relatando suas ações"}

A análise das falas permitiu-nos identificar as atividades desenvolvidas, por cada um dos membros que integram a equipe, perante as famílias que lidam com a depressão. Embora a equipe tenha um trabalho planejado e integrado, atribuições específicas são assumidas pelos membros que a compõem, respeitando as singularidades de cada um e o tipo de assistência que é prestada, nos consultórios de saúde mental, com ênfase na promoção da saúde e prevenção da doença. As atividades desenvolvidas incluem, geralmente, atenção direta dos casos detectados, trabalho nas escolas de ensino, psicoeducação ao paciente e família, visitas domiciliares, encaminhamentos dos casos graves ao Instituto de Saúde mental "Honório Delgado-Hideyo Noguchi entre outras atividades.

"Dentro do Departamento de Saúde Mental comunitária 2/3 do pessoal realizam atividades de promoção da saúde e prevenção das alterações e 1/3 da equipe se dedica à atenção direta, ou seja, a recuperação do doente". (Psiquiatra) 
"Temos a responsabilidade da parte educativa. Quando o paciente chega, primeiro se faz o estudo social para conhecer a dinâmica familiar e aspectos sócio-econômicos. A partir destas realizamos visitas domiciliarias e educação". (Assistente Social A)

"O trabalho nas Escolas é só um aspecto do trabalho preventivo do psicólogo na comunidade. Os casos detectados são encaminhados ao consultório do Centro de Saúde onde se oferece aconselhamento, trabalho grupal e os integramos a grupos de trabalho preventivo. Os casos mais graves são enviados ao Instituto Nacional de Salud Mental ou ao Centro de Saúde para serem atendidos pelo psiquiatra". (P sicólogo)

\section{"Comentando a interação com a família"}

Ao discorrerem sobre a comunicação do profissional com a família, alguns o fizeram a partir da sua própria perspectiva. Exemplificando, temos o caso do psiquiatra cujo depoimento reflete com muita clareza a sua tendência biomédica, organicista ao se referir que sua atividade centra-se em aspectos diretivos e farmacológicos. Outros referiram-se a quem mais informa sobre os clientes, sendo a mãe evidenciada como esta pessoa, o que é comum a diversas culturas, nas quais a mulher no papel de mãe é quem assume o cuidado dos membros.

Paralelamente, a enfermeira e assistente social, mulheres, são também umas das apontadas como sendo as participantes mais indicadas para trabalhar com a família.

"Desde a perspectiva médica o assunto é concreto: diretivo e farmacológico". (Psiquiatra)

"Provavelmente quem tem o perfil para trabalhar com a família são as enfermeiras e a assistente social...Muito melhor!..." (Psiquiatra)

"Durante a interação quem mais participa é a mãe que está mais alerta do que sucede com seu filho". (Psicólogo)

"A participação da família é muito limitada. De todos os membros é a mãe quem mais deseja a melhora do filho. Encontra-se mais resistência nos pais". (Assistente Social A)

\section{TEMA CULTURAL}

"Integrando uma equipe apesar das diferenças"

Perpassando pelas categorias, percebemos que os membros da equipe interdisciplinar têm pontos de convergência e divergência sobre o que encontram no seu dia-a-dia. Descrevem como é, para a família, a percepção da depressão como doença; relatam suas ações no cotidiano e comentam sobre o conteúdo da interação com a família.

Vencem, porém, os obstáculos e mantém um trabalho de equipe, no qual existe respeito mútuo apesar de alguns pontos de vista diferentes entre eles. A complementaridade é percebida pelos membros do grupo, como algo importante o que evita a duplicidade de ações. Percebe-se também, com muita clareza, a função do médico desempenhado sob os moldes do modelo biomédico, assumindo o papel de "chefe" da equipe.

"Nosso trabalho, entre todos os membros da equipe, é complementar, mais do que duplicidade de funções. Sobretudo pela ênfase colocada na parte preventiva promocional". (Psicólogo)

"O trabalho do psiquiatra é avaliar o paciente e dar-Ihe tratamento médico, porque há outros profissionais que oferecem outros tipos de tratamento que são também complementares". (Psiquiatra) 


\section{CONSIDERAÇÕES FINAIS}

Pudemos evidenciar o esforço dos elementos da equipe para manterem o atendimento da pessoa com depressão, já aceita como doença. Na comunidade articulam entre eles o atendimento das diversas dimensões do ser humano, procurando respeitar suas crenças e valores. Isto torna-se possível quando o atendimento se dá no habitat natural de cada um.

Aos poucos conscientizam a comunidade e as famílias sobre o que é a depressão e como esta se manifesta, só encaminhando o portador da depressão para a assistência hospitalar quando todos os recursos comunitários se esgotam.

Torna-se evidente a importância da relação entre profissional doente e família, que deve ser estabelecida de acordo com o repertório de cada pessoa, para que eles se sintam compreendidos, aceitos e tratados num clima de respeito mútuo, facilitando assim a aceitação da doença e adesão ao tratamento do paciente e colaboração da família neste processo. Acreditamos que isto seja possível se desde o primeiro contato de quaisquer membro da equipe interdisciplinar com o paciente e/ou família, exista a vontade de fornecer um cuidado humanizado que vai além de um simples interrogatório para o estabelecimento de uma terapêutica medicamentosa ou mesmo psicológica.

A percepção da família convivendo com a depressão é descrita segundo a visão de cada um, ou seja, segundo a função de cada um deles.

A pesar das características individuais conseguem trabalhar num clima de respeito mútuo considerando complementaridade de saberes.

Aparentemente não manifestaram percepção da família como unidade sendo atendida por equipe interdisciplinar.

ABSTRACT: Depression continues to increase progressively in society and affects not only an individual butalso his family, and this fact makes this issue turn from a primary level of attention to a priority one. O ur objective was to get to know how the members of an intra-discipline community team describe their experiences by working with families that live in an environment of depression. We used the ethnographic method and in order to obtain data we used a form containing and open question followed by a graph. We made the following cultural categories: "Describing what is found", "Signaling the amount of time the family takes to perceive the signs of people with the mental sickness", "Describing their actions", Commenting on the interaction with the family", and as a cultural theme: "Integrating a team regardless of the differences". According to the study, although the members might get a job in an intra-disciplinary team, the experience is described according to the vision or function of each member. Nevertheless, they are able to obtain global information about the patient in a climate of mutual respect considering the complementary of knowledge.

KEY WORDS: Pacient care team; Family; Depression.

RESUMEN: La depresión viene aumentando progresivamente en la sociedad y afecta no sólo al enfermo sinó también a su familia, hechos que la tornan prioridad de la atención a nivel primario. Nuestro objetivo fué conocer cómo los integrantes de un equipo interdisciplinario comunitario describen su experiencia de trabalho con familias conviviendo con la depresión.Usamos el método etnográfico y para la obtención de datos un formulario con una pregunta abierta seguida de un esquema. Construímos las categorías culturais: "Describiendo lo que encuentran", "Señalando la demora de la familia para percibir las manifestaciones de las personas con la enfermedad", "Relatando sus acciones", "Comentando la interacción con la familia" y como tema cultural: "Integrando un equipo a pesar de las diferencias".S egún el estudo, no obstante que los miembros consigan 
mantener un trabajo de equipo interdisciplinario, la experiencia es descrita conforme la visión o función de cada uno. A pesar de esto consiguen obtener una información global del paciente en un clima de respeto mutuo considerando la complementaridad de saberes.

PALABRAS CLAVES: Grupo de atención al paciente; Familia; Depresion.

\section{REFERÊNCIAS}

1 ALMENDRAS, I. Bienestar o depresión? . Montevideo: Ediciones del Milenio, 2001.

2 CAPRA, F. 0 modelo biomédico. In: O ponto de mutação. 25.ed. Cidade: Editora, 1982. cap.5, p. 116-155.

3 HUAMAN, J . Programa de rehabilitación psico-social. In: INSTITUTO DE SALUD MENTAL HONÓRIO DELGADO-HIDEYO NOGUCHI. Anales de salud mental, Lima, 1996. p.241-284.

4 INSTITUTO DE SALUD MENTAL HONORIO DELGADO-HIDEYO NOGUCHI. Orientación delaatención Psiquiátrica en Sudamérica. Lima: OPAS/OMS, 1995.

5 KAPLAN, H. Trastornos del estado de ánimo. In: Ed. Médica Panamericana, 1996. cap.15, p. 537-545. Sinopsis de psiquiatria: ciencias de la conducta. 7.ed. Buenos Aires:

6 MACHER, E. La salud mental en el Perú. In: INSTITUTO NACIONAL DE SALUD ME NTAL HONORIO DELGADO-HIDEYO NOGUCHI. Anales de salud mental, Lima, 1996. p.257-263.

7 MENDOZA, M. etal. Depresión. In: INSTITUTO NACIONAL DE SALUD MENTAL HONORIO DELGADO-HIDEYO NOGUCHI. Diagnóstico situacional de la salud mental en el Distrito de Independencia. Lima, 2000. cap. 15, p.257-266.

8 MORENO, R. A., MORENO, D. H. Prática psiquiátrica em consultório. Rev. Esc. Enferm. USP, São Paulo, v.43, p. 44-53, 1999.

9 ORGANIZACIÓN MUNDIAL DE LA SALUD. Reestructuración dela atención psiquiátrica en América Latina. Washington, 1995.

10 PERU. Ministerio de la Salud. Lineamientos para la acción en Salud Mental. Lima, 2002.

11 PEZO SILVA, M. C., STEFANELLI, M. C. Estudo preliminar sobre os fatores que levam a reinternaVão de pacientes em hospitais psiquiátricos. Rev. Paul. Enferm., São Paulo, v.10, n.1, p.21-28, 1991.

12 PEZO SILVA, M.C., STEFANELLI, M. C. A depressão provocando mudanças na família. In: CONGRESSO NACIONAL DE ENFERMAGEM, 53, 2001, Curitiba. Anais... Curitiba:ABEn, 2001. 1 CD ROM.

13 PEZO SILVA, M. C., STEFANELLI, M.C.,ARANTES, E. C. O deprimido no convívio familiar. In: SEMINÁRIO NACIONALDE PESQUISA EM ENFERMAGEM, 2001. Anais... Belém:ABEn, 2001. 1 CD ROM.

14 STEFANELLI, M. C. etal. A enfermeira psiquiátrica e a equipe multiprofissional. Rev. Esc. Enferm. USP, São Paulo, v. 19, n.2, p.127-134, 1985.

15 STUART, G. W. A enfermagem Psiquiátrica na prática: padrões de desempenho profissional. In: Psiquiátrica: princípios e prática. 6.ed. Porto Alegre: Artmed, 2001. p. 222-237.

16 WORLD HEALTH ORGANIZATION. Raising Awareness, fighting stigma, improving care. Washington, 2001. 